\title{
Patch-type large strain sensor using elastomeric composite filled with carbon nanofibers
}

\author{
Tetsuo Yasuoka* \\ Department of Mechanical Sciences \& Engineering, Tokyo Institute of Technology, Tokyo 152-8552, Japan.
}

\section{Yoshinobu Shimamura**}

Department of Mechanical Engineering, Shizuoka University, Shizuoka 432-8561, Japan.

\author{
Akira Todoroki*** \\ Department of Mechanical Sciences \& Engineering, Tokyo Institute of Technology, Tokyo 152-8552, Japan.
}

\begin{abstract}
Carbon nanofibers (CNFs) are electrically conductive. When CNFs are used as fillers in resin, this electrical conductivity can be yielded without adversely affecting the mechanical properties of the resin. When an elastomer is adopted as the resin, a conductive elastomer can then be produced. Due to its flexibility and conductive properties, a large strain sensor based on changes in resistivity may be produced, for strain sensing in flexible structures. In this study, a patch-type large strain sensor using resistivity change in a CNF/elastomer composite was proposed. The measurement limits of the sensor were investigated experimentally, and the limit was found to be $40 \%$, which greatly exceeded the limits of conventional metal-foiled strain gages. Also, the proposed CNF/elastomer large strain sensor can be used to measure flexible materials, while conventional strain gages cannot be used to measure such strains.
\end{abstract}

Key words: nanocomposite, carbon nanofiber, strain sensing, elastomer

\section{Introduction}

Carbon nanofibers (CNFs) are used as fillers in nanocomposites. Carbon nanotubes are a type of CNF. CNFs are electrically conductive, and resins filled with CNFs are also conductive. Many researchers have studied the applicability of CNFs in functional materials [1-16]. For example, electromagnetic shielding using a CNF-based composite [1], and an electrical resistance-based sensor $[3,4]$ have been developed.

It is well known that the CNF-based composites are electrically conductive when the CNF volume content is as low as a few percent [5-15]. This is a dramatically low filler content requirement, when compared with the required content of conventional fillers, such as carbon black [14]. The reason for this is that the CNF diameter is small, and the
CNF shape has a high aspect ratio. Therefore, the electrical conductivity can be produced without adversely affecting the mechanical properties of the resin. When an elastomer is adopted as the matrix, then a conductive elastomer can be produced [15]. When both the flexibility and the conductivity of this material are used, a large strain sensor based on the change of resistivity may be produced, and strain in membrane structures, such as hot air balloons or solar sails, may be measured; conventional strain gages cannot measure these strains.

In this study, a patch-type large strain sensor based on the resistivity change in a $\mathrm{CNF} /$ elastomer composite was proposed, and the measurement limits of the sensor were investigated experimentally. Also, the validity of the sensor in terms of the deformation followability was demonstrated, by comparison with a traditional patch-type strain gage.
This is an Open Access article distributed under the terms of the Creative Commons Attribution Non-Commercial License (http://creativecommons.org/licenses/by$\mathrm{nc} / 3.0 /$ which permits unrestricted non-commercial use, distribution, and reproduction in any medium, provided the original work is properly cited. cc * Ph.D student; Corresponding Author : tyasuoka@ginza.mes.titech.ac.jp ** Associate Professor $* * *$ Professor 


\section{Large strain sensor using CNF/elastomer composite}

\section{1 Fabrication of the CNF/elastomer composite}

In this study, vapor grown carbon fiber (VGCF) supplied by Showa Denko K.K. was used as the CNF filler. The material properties are shown in Table 1. VGCF is a kind of carbon nanofiber with a diameter of approximately $100 \mathrm{~nm}$. VGCF was discovered by Oberlin et al. in 1974 [17]. VGCF is graphitized by heating at high temperatures of $2000-2800^{\circ} \mathrm{C}$, and its structure is the same as that of multi-walled carbon nanotubes. The aspect ratio of VGCF is smaller than that of general carbon nanotubes. VGCF therefore has good dispersion properties, when it fills in the matrix. A picture of VGCF produced by scanning electron microscopy (SEM) is presented in Fig. 1.

Table 1. Attributes of VGCF.

\begin{tabular}{cc}
\hline Diameter of fiber & $150 \mathrm{~nm}$ \\
Length of fiber & $10-20 \mu \mathrm{m}$ \\
Aspect ratio & $10-500$ \\
Fiber density & $2.0 \mathrm{~g} / \mathrm{cm}^{3}$ \\
Bulk density & $0.04 \mathrm{~g} / \mathrm{cm}^{3}$ \\
Fiber resistivity & $1 \times 10^{-4} \Omega \mathrm{cm}$ \\
Bulk resistivity & $0.012 \Omega \mathrm{cm}$ \\
\hline
\end{tabular}

Table 2. Properties of ME-113/XH-1859-2 elastomer.

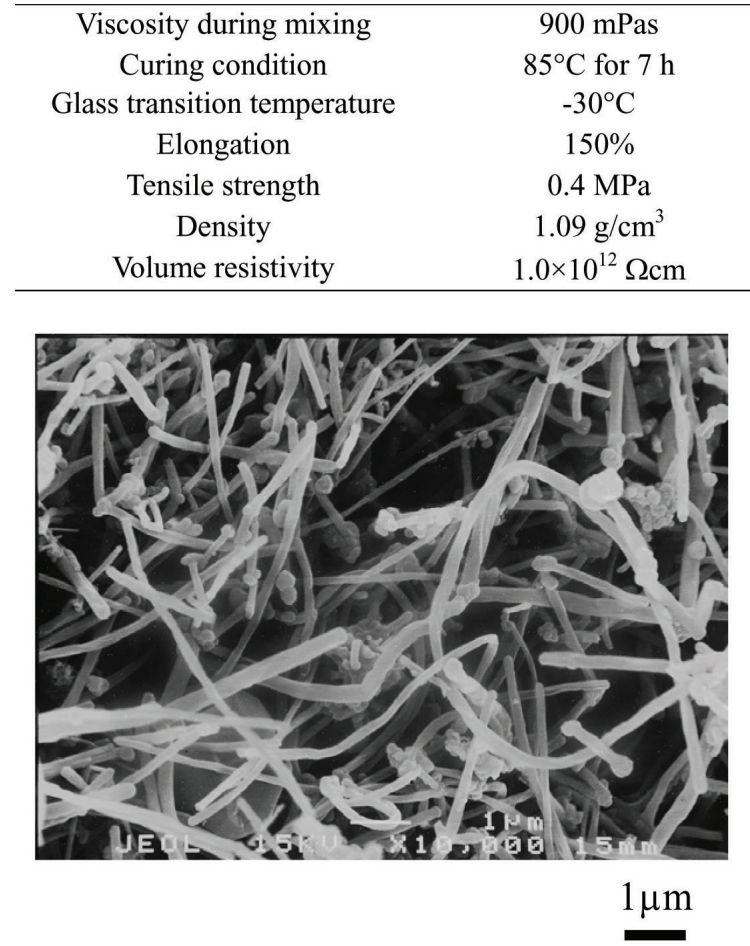

Fig. 1. Scanning electron microscope image of VGCF.
A flexible epoxy (ME-113/XH-1859-2, Nippon Pelnox Corp.) was adopted as the elastomer for the composite. The epoxy is fabricated by mixing resin with a hardener, and has a high flexibility property, with elongation of $150 \%$. The material properties are shown in Table 2.

The configuration of the proposed large strain sensor is presented in Fig. 2. A patch-type structure similar to that of traditional metal-foil strain gages was applied. The copper foil electrodes were bonded by co-curing both ends of the $\mathrm{CNF}$ /elastomer sensor. The CNF volume fraction is 6.0 weight percent (wt.\%) with consideration of the resistivity. In the case of the composite in this study, filler content of more than $2 \mathrm{wt} . \%$ is required for electrical conductivity to occur.

The fabrication procedure for the proposed sensor is as follows. First, the CNFs were dried at $130^{\circ} \mathrm{C}$ for $3 \mathrm{~h}$. Next, the epoxy resin, the hardener and the CNFs were mixed in a planetary-type mixer (NBK-1, Nihonseiki Kaisha Ltd.) at $2000 \mathrm{rpm}$ for $10 \mathrm{~min}$. Degassing and dispersion were

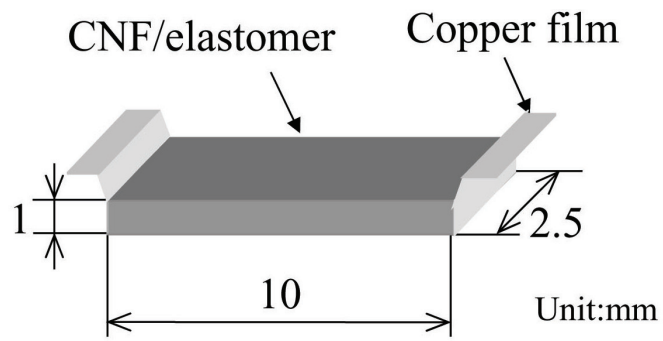

Fig. 2. Configuration of large strain sensor.

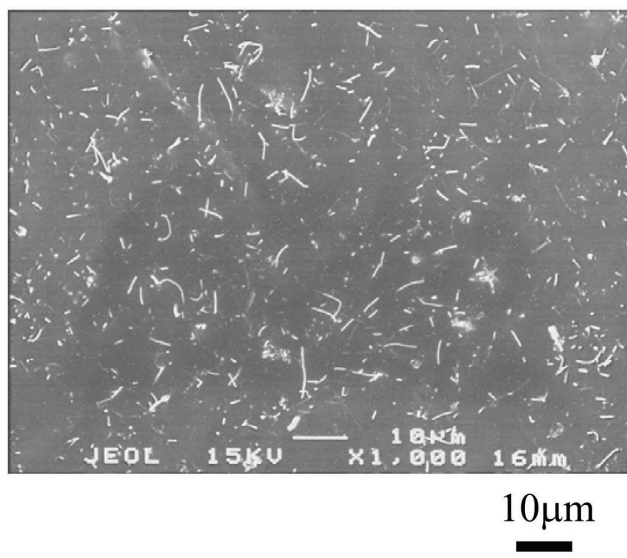

Fig. 3. SEM observation of CNF dispersion (4.0 wt.\%).

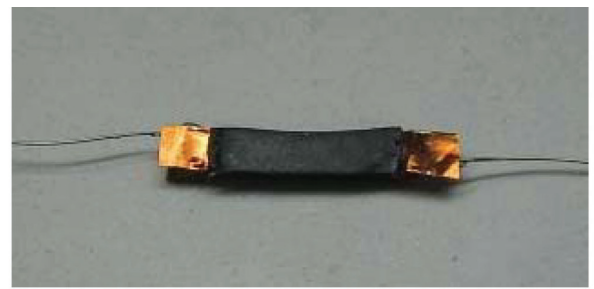

Fig. 4. Picture of the proposed sensor. 
conducted simultaneously by the mixer. Then, the mixture was poured into a silicon mold, and cured with electrodes in a furnace at $85^{\circ} \mathrm{C}$ for $7 \mathrm{~h}$. After curing, the material was cut into the shape shown in Fig. 2, and a lead wire was soldered to the electrodes. Good dispersion of the CNFs was achieved using this procedure, as confirmed by the SEM image shown in Fig. 3. A picture of the fabricated large strain sensor is shown in Fig. 4.

\section{2 Test method for large strain measurement}

The strain measurement limitations of the fabricated large strain sensor were investigated by a quasi-static tensile test.

Two types of specimens were prepared. The shapes and dimensions of these specimens are portrayed in Fig. 5 and Fig. 6. The specimen shown in Fig. 5, which is named "type A", has a structure where the sensor is sandwiched by rubber plates. The properties of these rubber plates are shown in Table 3. The type A specimen is symmetrical, and the effects
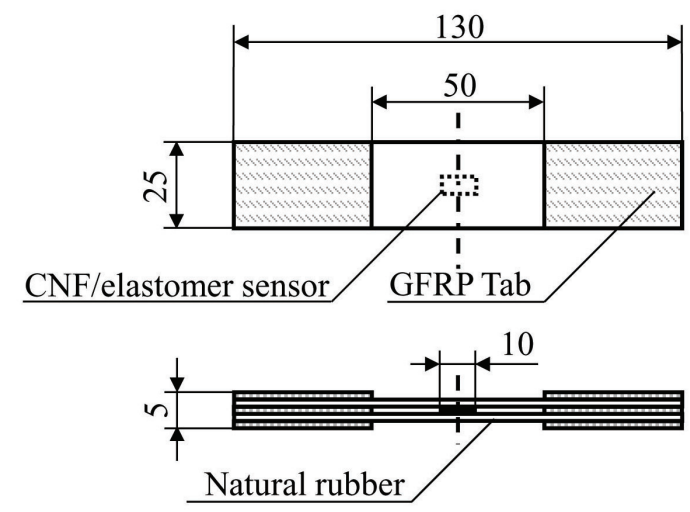

Fig. 5. Type A specimen configuration.
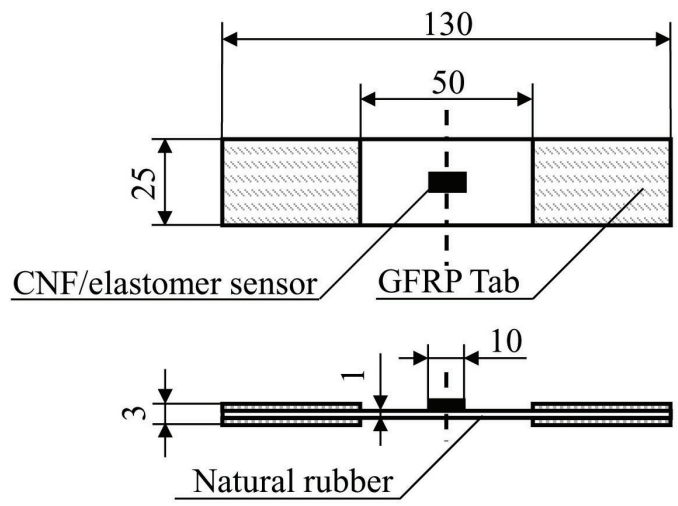

Fig. 6. Type B specimen configuration.

Table 3. Properties of natural rubber.

\begin{tabular}{cc}
\hline Elongation & $300 \%$ \\
Tensile strength & $3.7 \mathrm{MPa}$ \\
Poisson's ratio & 0.49 \\
\hline
\end{tabular}

of bending deformation can be extinguished during the tensile tests. The specimen shown in Fig. 6, which is named "type B", is fabricated by attaching the sensor to one side of the rubber plate, which is assumed to be applied to the actual structures. As an adhesive, a flexible epoxy was used, which is the same material as that of the matrix, and the sensor was attached by covering it, together with the electrodes.

The test method is as follows. A tensile load was applied in the longitudinal direction of the specimen. The electrical resistance change of the sensor was then measured, using an LCR meter (LCR HiTester 3522, Hioki E.E. Corp.). The strain was measured, based on the change in the gage length marked on the rubber plate. The crosshead speed was 0.5 $\mathrm{mm} / \mathrm{min}$. Tensile loading was applied continuously, up to the failure point of the sensor.

\section{3 Test results and discussion}

Test results for the type A specimens are shown in Fig. 7 , and those for the type B specimens are shown in Fig. 8. The electrical resistance change results were plotted on logarithmic scales, in each case. The authors have previously reported that the electrical resistance of CNFbased composites under tensile strain conditions changes exponentially, and the mechanism of this behavior can be described based on percolation theory and tunneling effects [18]. The tests were conducted with three specimens for each of the two types of specimen, and the results for both types followed similar curves. The initial values of the electrical resistance of the sensors are $80 \mathrm{k} \Omega, 113 \mathrm{k} \Omega$ and $120 \mathrm{k} \Omega$ for type A, and $62 \mathrm{k} \Omega, 80 \mathrm{k} \Omega$ and $130 \mathrm{k} \Omega$ for type B. The initial electrical resistance values of each sensor are different, because a slight difference in the CNF content can cause a significant change in the electrical resistance. The failure strain was defined as the strain at the time of a sudden increase in electrical resistance, caused by sensor failure. The failure strain for type A was approximately $20 \%$, while that for

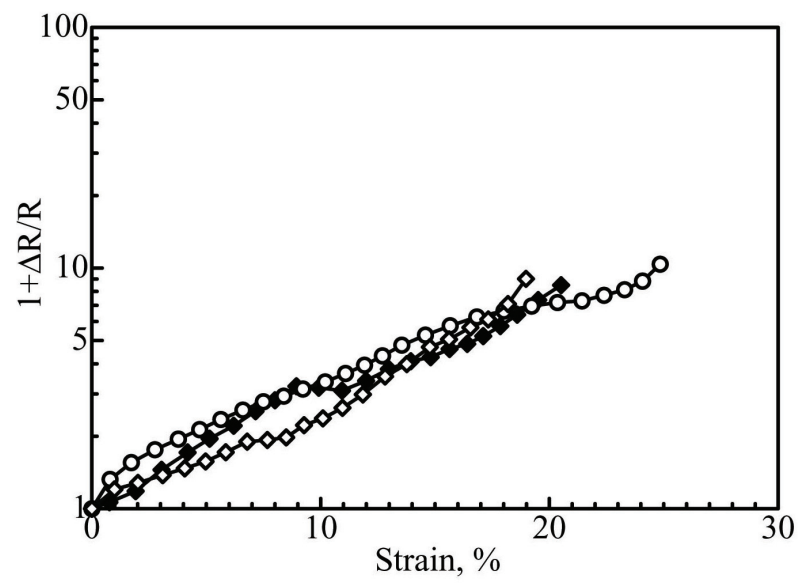

Fig. 7. Experimental results of electrical resistance change under tensile strain (for type A). 
type B was approximately $40 \%$, which greatly exceeded the limit for conventional metal foil-based strain gages of $20 \%$. The proposed large strain sensor can therefore measure up to twice the strain limit of conventional strain gages.

Specimen failure occurred at the adhesive area of the electrodes, as confirmed by visual observation. For a type A specimen, the sensor constraint is larger than that of type B, because of the sensor's sandwich structure. This constraint leads to locally excessive strain around the electrodes, and, therefore, the type A specimen failed at relatively small strain values, when compared with the type B specimen.

When comparing the results shown in Fig. 7 and Fig. 8 , the values of the electrical resistance change tended

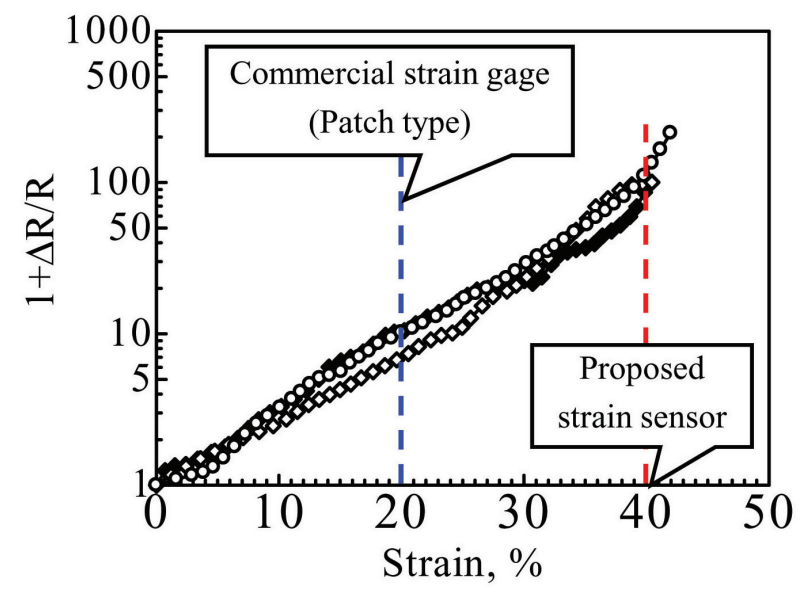

Fig. 8. Experimental results of electrical resistance change under tensile strain (for type B). to be quantitatively similar. This means that the effect of bending deformation is also negligible, in the case of the unsymmetrical specimen of type $B$. The reason for this behavior is that the sensor rigidity is sufficiently small, relative to that of the rubber plate. In other words, the proposed sensor can be applied to low rigidity materials, such as rubber or flexible materials.

\section{4 Comparison with the conventional large strain gage}

Traditionally, metal-foiled large strain gages are used to measure the plastic deformation of metals or plastics. The CNF/elastomer strain sensor proposed in this study can measure up to $40 \%$ strain, which is twice the limit of conventional strain gages. In this section, the CNF/elastomer strain sensor is compared with conventional strain gages, in terms of deformation followability.

For comparison, a metal-foiled large strain gage (KLM6-120-A9) supplied by Kyowa Electronic Instruments was adopted as the conventional strain gage. The strain gage was attached to the type B specimen as a substitute for the proposed sensor, and the gage was bonded using a special adhesive (EC-30, Kyowa Electronic Instruments). Three different kinds of specimen were prepared: a type B specimen attached to the proposed CNF/elastomer strain sensor, a specimen attached to the metal-foiled large strain gage, and a specimen without any sensor (rubber plate-only case).

Tensile loading was applied in the longitudinal direction of the specimens. Strain was measured at every $2.5 \mathrm{~mm}$ of

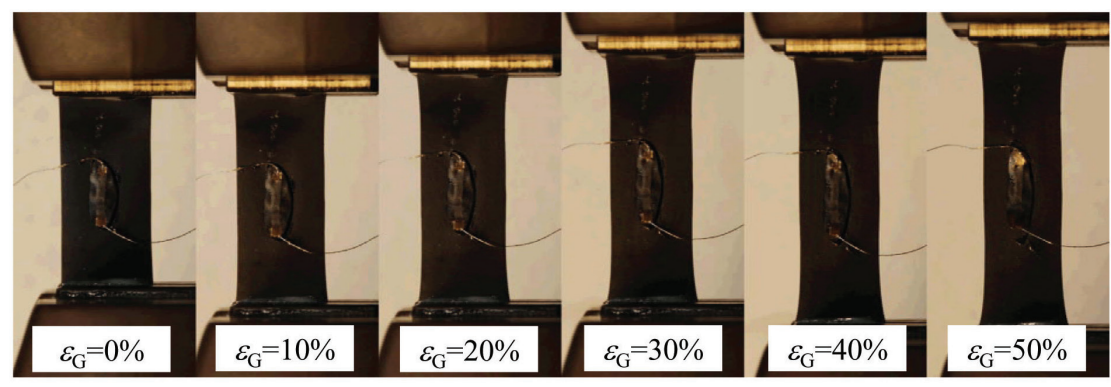

Fig. 9. Images of deformation of rubber with proposed large strain sensor.

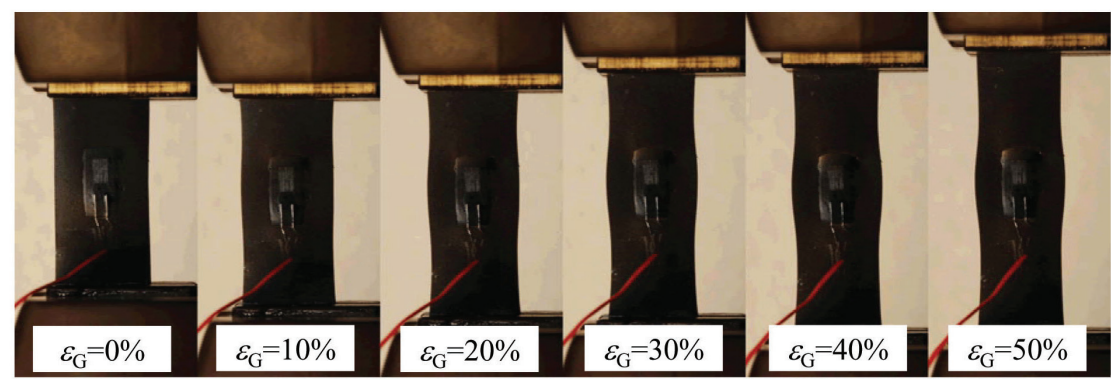

Fig. 10. Images of deformation of rubber with conventional large strain gage. 


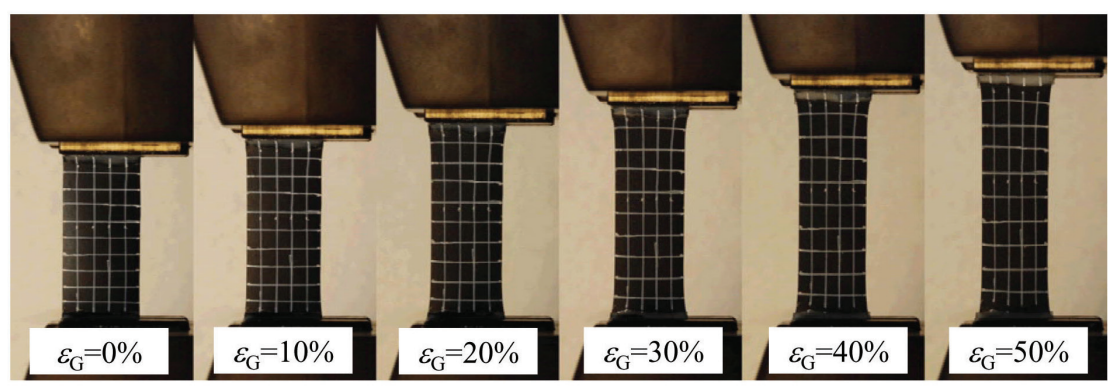

Fig. 11. Images of deformation of rubber without a strain gage.

displacement, and a photograph was taken at every $5.0 \mathrm{~mm}$ of displacement. Here, the gage length of the specimen used to measure the strain is $50 \mathrm{~mm}$, and thus a displacement of $2.5 \mathrm{~mm}$ is equivalent to an $\varepsilon_{\mathrm{G}}$ (the rate of gage length change) of $5 \%$. The strain was measured based on the electrical output for the metal-foiled strain gage specimen, and on the gage length change marked on the rubber plate for the other specimens.

The measurement results are shown in Fig. 9, Fig. 10 and Fig. 11. Figure 9 shows a photo of the case of the proposed CNF/elastomer strain sensor, Fig. 10 presents the case of the metal-foiled large strain gage, and Fig. 11 shows the rubber plate-only case. The metal-foiled large strain gage interfered with the deformation of the rubber plate. However, the proposed CNF/elastomer strain sensor

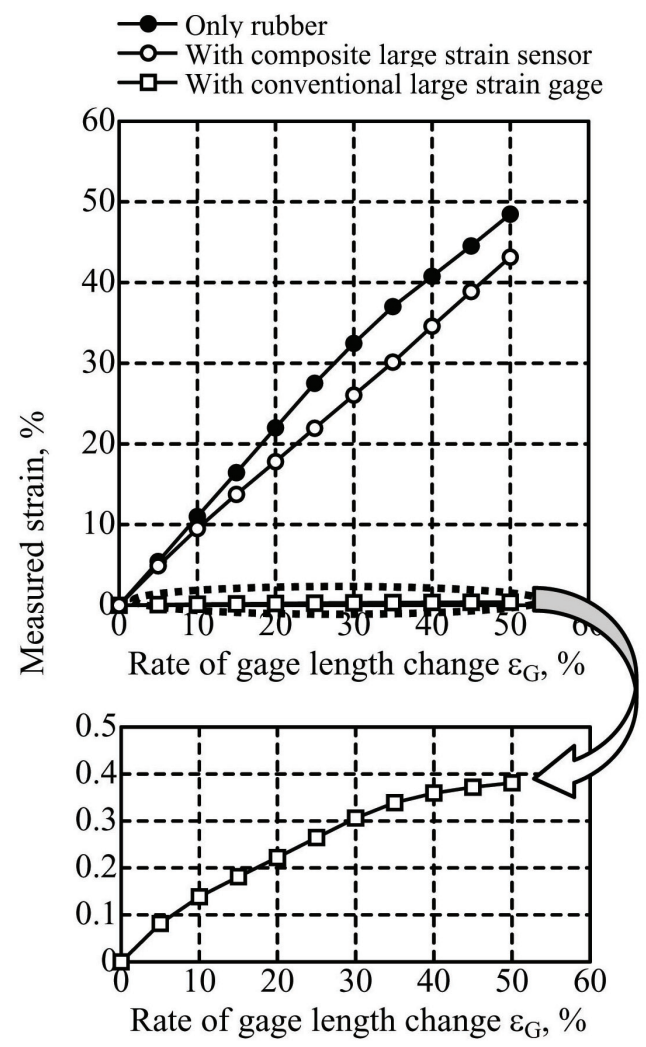

Fig. 12. Measured strain vs. gage length change $\varepsilon$ G. followed the deformation of the rubber plate, because of its flexibility. Figure 12 plots the relationships of the measured strain versus the gauge length change $\varepsilon_{\mathrm{G}}$. The metal-foiled strain gage could not measure the strain, because the strain gage had high rigidity, compared to the rubber plate. In contrast, the curve of the proposed large strain sensor in Fig. 12 followed the curve of the rubber plate. This means that the proposed sensor could measure the strain of the rubber plate. From these results, it was shown that the proposed $\mathrm{CNF}$ /elastomer large strain sensor may be used to measure flexible materials, such as rubber or membrane structures, while conventional strain gages cannot be used to measure these strains.

\section{Conclusions}

A patch-type large strain sensor using the resistivity change of a CNF/elastomer composite was proposed. The measurement limit of the sensor was experimentally investigated, and was found to be $40 \%$, which was far greater than the limit of conventional metal-foiled strain gages. The $\mathrm{CNF}$ /elastomer large strain sensor was also compared with conventional strain gages, in terms of their deformation followability. The results for the CNF/elastomer strain sensor indicated good followability to the rubber plate. The proposed CNF/elastomer large strain sensor could be used to measure strain in flexible materials, while conventional strain gages cannot.

\section{References}

[1] Katsumata, M., Yamanashi, H., Ushijima H., and Endo M., "Electrical resistance of electroconductive plastic composite with carbon fiber filler", Electrical Engineering in Japan, Vol. 114, Issue 5, 1994, pp. 17-23.

[2] Katsumata, M., Endo M., and Ushijima H., "Epoxy composites using vapor-grown carbon fiber fillers for advanced electroconductive adhesive agents", Journal of Materials Research, Vol. 9, No. 4, 1994, pp. 841-843. 
[3] Abraham, J. K., Philip, B., Witchurch, A., Varadan, V. K., and Reddy, C. C., "A compact wireless gas sensor using a carbon nanotube/PMMA thin film chemiresistor", Smart Materials and Structures, Vol. 13, Issue 5, 2004, pp. 10451049.

[4] Yoon, H., Xie, J., Abraham, J. K., Varadan, V. K., and Ruffin, P. B., "Passive wireless sensors using electrical transition of carbon nanotube junctions in polymer matrix", Smart Materials and Structures, Vol. 15, Issue 5, 2006, pp. S14-S20.

[5] Sandler, J., Shaffer, M. S. P., Prasse, T., Bauhofer, W., Schulte, K. and Windle, A. H., "Development of a dispersion process for carbon nanotubes in an epoxy matrix and the resulting electrical properties", Polymer, Vol. 40, Issue 21, 1999, pp. 5967-5971.

[6] Benoit, J. M., Corraze, B., Lefrant, S., Blau, W. J., Bernier, P., and Chauvet, O., "Transport properties of PMMA-carbon nanotubes composites", Synthetic Metals, Vol. 121, No. 1-3, 2001, pp. 1215-1216.

[7] Kilbride, B. E., Coleman, J. N., Fraysse, J., Fournet, P., Cadek, M., Drury, A., Hultzler, S., Roth, S., and Blau, W. J., "Experimental observation of scaling laws for alternating current and direct current conductivity in polymer-carbon nanotube composite thin films", Journal of Applied Physics, Vol. 92, Issue 7, 2002, pp. 4024-4030.

[8] Barrau, S., Demont, P., Peigney, A., Laurent, C., and Lacabanne, C., "DC and AC conductivity of carbon nanotubes-polyepoxy composites", Macromolecules, Vol. 36, No. 14, 2003, pp. 5187-5194.

[9] Rul, S., Lefevre-Schlick, F., Capria, E., Laurent, C., and Peigney, A., "Percolation of single-walled carbon nanotubes in ceramic matrix nanocomposites", Acta Materialia, Vol. 52, Issue 4, 2004, pp. 1061-1067.

[10] Du, F., Fischer, J. E., and Winey, K. I., "Effect of nanotube alignment on percolation conductivity in carbon nanotube/polymer composites", Phys. Rev. B, Vol. 72, Issue
12, 2005, p. 121404.

[11] Gordeyev, S. A., Macedo, F. J., Ferreira, J. A., van Hattum, F. W. J., and Bernardo, C. A., "Transport properties of polymer-vapour grown carbon fibre composites", Physica $B$, Vol. 279, Issues 1-3, 2000, pp. 33-36.

[12] Finegan, I. C., and Tibbetts, G. G., "Electrical conductivity of vapor-grown carbon fiber/thermoplastic composites", J. Mater. Res., Vol. 16, Issue 6, 2001, pp. 16681674.

[13] Wu, S. H., Toshiaki, N., Kurashiki, K., Ni, Q. Q., Iwamoto, M., and Fujii, Y., "Conductivity stability of carbon nanofiber/unsaturated polyester nanocomposites", Advanced Composite Materials, Vol. 16, Issue 3, 2007, pp. 195-206.

[14] Enomoto, K., Yasuhara, T., Ohtake, N., and Kato, K., "Injection molding of polystyrene matrix composites filled with vapor grown carbon fiber", JSME International Journal Series A, Vol. 46, No. 3, 2003, pp. 353-358.

[15] Shimamura, Y., Kageyama, K., Tohgo, K., and Fujii, T., "Cyclic behavior of electrical resistance type low stiffness, large strain sensor by using carbon nanofiber/flexible epoxy composite", Key Engineering Materials, Vol. 462-463, 2011, pp. 1200-1205.

[16] Park, J. M., Kim, D. S., Lee, J. R., and Kim, T. W., "Nondestructive damage sensitivity and reinforcing effect of carbon nanotube/epoxy composites using electromicromechanical technique", Materials Science and Engineering: $C$, Vol. 23, Issues 6-8, 2003, pp. 971-975.

[17] Oberlin, A., Endo, M., and Koyama, T., "Filamentous growth of carbon through benzene decomposition", Journal of Crystal Growth, Vol. 32, Issue 3, 1976, pp. 335-349.

[18] Yasuoka, T., Shimamura, Y., and Todoroki, A., "Electrical Resistance Change under Strain of CNF/FlexibleEpoxy Composite", Advanced Composite Materials, Vol. 19, Issue 2, 2010, pp. 123-138. 